PREHOSPITAL CARE

\title{
Educating the ambulance technician, paramedic, and clinical supervisor: using factor analysis to inform the curriculum
}

\section{T Kilner}

Emerg Med J 2004;21:379-385. doi: 10.1136/emj.2003.009605

\begin{abstract}
Objectives: This project aims to use information about the desirable attributes of the ambulance technician, paramedic, and clinical supervisor to inform future curriculum development.

Methods: Data generated by a Delphi study investigating the desirable attributes of ambulance technician, paramedic, and clinical supervisor were subject to factor analysis to explore inter-relations between the variables or desirable attributes. Variables that loaded onto any factor at a correlation level of $>0.3$ were included in the analysis.

Results: Three factors emerged in each of the occupational groups. In respect of the ambulance technician these factors may be described as; core professional skills, individual and collaborative approaches to health and safety, and the management of self and clinical situations. For the paramedic the themes are; core professional skills, management of self and clinical situations, and approaches to health and safety. For the clinical supervisor there is again a theme described as core professional skills, with a further two themes described as role model and lifelong learning.

Conclusions: The profile of desirable attributes emerging from this study are remarkably similar to the generic benchmark statements for health care programmes outlined by the Quality Assurance Agency for Higher Education. It seems that a case is emerging for a revision of the curriculum currently used for the education and training of ambulance staff, which is more suited to a consumer led health service and which reflects the broader professional base seen in programmes associated with other healthcare professions. This study has suggested outline content, and module structure for the education of the technician, paramedic, and clinical supervisor, based on empirical evidence.
\end{abstract}

Correspondence to: MrT Kilner, The University of Birmingham, School of Health Sciences,

Edgbaston, Birmingham B15 2TT, UK;

t.m.kilner@bham.ac.uk

Accepted for publication 15 January 2004 l: 1966 a committee, chaired by Dr E L M Millar, reported to the Minister for Health on the equipment and training of staff in the NHS ambulance service. ${ }^{12}$ These reports were instrumental in both setting and improving standards in the training of ambulance staff. Before this in the post-war years all that was required of ambulance staff was a driving licence and an agreement to undertake a first aid certificate once in service. There are however reports of staff working for many months before undertaking a first aid certificate, and so working without any healthcare training whatsoever. ${ }^{3}$

The working party chaired by Millar, after a number of discussions and consideration of written evidence submitted by key stakeholders, recommended a programme of basic training lasting eight weeks although two weeks were to be dedicated to civil defence training. The course aimed to provide intensive first aid training with considerable emphasis on practical work. Additional general and technical subjects, much of which was procedural or administrative, supported this. Box 1 outlines the programme. After 12 months of experience, a review would take place and the student subject to oral and practical tests. If the student met the required standard they would receive the award of Ambulance Services Proficiency Certificate, commonly referred to as the "Millar Certificate". The Millar Certificate was broadly similar to the contemporary technician qualification and at the time was the basic qualification for the ambulance man or woman.

This programme was operated for many years and has now evolved into the current Institute of Health and Care Development (IHCD) ambulance technician programme, ${ }^{4}$ which is outlined in box 2. This programme is highly practical and typically lasts no less than six weeks for the clinical component and three weeks for the driving element. Again the final award is not made until the student has completed 12 months of clinical practice in an operational role after the basic training course.

In Belfast, at around the same time Millar reported to the Minister of Health. Steps were being taken to reduce mortality from myocardial infarction in the community by taking the coronary care unit to the patient in the form of a specially equipped ambulance. Initially clinical care was delivered by medical and nursing staff, ${ }^{5}$ but it became evident over time that these schemes could be operated by appropriately trained ambulance staff.

There is no doubt that this work was influential in informing the development of the concept of extended training for ambulance staff, which ultimately became what we now recognise as the ambulance paramedic. In the 1970s and the early part of the 1980s a number of services were developing local extended training programmes. After evaluation by the Department of Health and Social Security, predominantly based upon predicted costs and assumed benefits, ${ }^{6}$ a favoured model was approved and became the basis of paramedic training. The current IHCD paramedic programme ${ }^{4}$ does not betray these coronary care roots, and places emphasis on clinical resuscitation skills including advanced airway skills, intravenous cannulation, the administration of drugs, and the provision of advanced life support. In addition to the classroom element of the programme, which lasts no less than the recommended 240 hours or six weeks, (outlined in box 3), there is a further 160 hours or four weeks of hospital based practical clinical skills. ${ }^{7}$

Lendrum and colleagues $^{8}$ in their study of a single metropolitan ambulance service concluded that the training 
Box 1 Course outline-the ambulance services proficiency certificate. After Millar, 1966

- First aid

- Induction

- Respiration

- Circulation

- Injuries

- General

- Procedures

- Apparatus

- Maternity

- Para-medical

- Medical nomenclature

- Care of seriously ill patients, surgical and medical

- Precautions in handling infectious diseases patients

- Care of patients under drug treatment

- Care of mentally ill patients

- Care of outpatients

- Ambulance work when under medical instruction or direct supervision

- Non-medical

- Information (ambulance service and the NHS)

- Communications (telephone and radio)

- Equipment

- The patient (professional conduct and relationship with patients)

- The hospital (practice and procedure within hospital)

- Liaison (with hospital transport officers and GPs)

- Lifting and carrying

- Light rescue

- Major accidents

- Special types of accidents

- Accidents and sudden illnesses (proceeding to the incident, procedure on arrival, gathering information)

- Infectious diseases

- Railway journeys

- Other forms of transport

- Removal of the dead

- Legal information

- Care and maintenance of vehicles

- Ambulance driving

of ambulance staff, and the paramedic in particular, placed considerable emphasis on the management of patients with life threatening conditions, especially cardiovascular and respiratory problems and resuscitation. This profile was not representative of the workload that ambulance personnel were encountering in their operational practice. Conversely little curriculum time was dedicated to those frequently encountered conditions that are not life threatening. Similarly, it has been shown in previous work ${ }^{9}$ that the desirable attributes of the technician, paramedic, and clinical supervisor extend beyond those that are provided by existing training curriculums.
Box 2 Components of the ambulance technician curriculum (IHCD ambulance personnel awards: training and common core syllabus for

ambulance personnel)

Driving training (mainly non-emergency) Advanced driving

\section{Ambulance technician I}

- Introduction to the body

- Liffing, handling, and equipment

- Respiratory system

- Circulatory system

- Cardiac monitoring

- Airway management and resuscitation

- Examination and assessment

- Assisting the paramedic

- Infants and children

\section{Ambulance technician II}

- Nervous system

- Skeletal system

- Musculoskeletal trauma

- Wounds and bleeding

- Infectious diseases

Ambulance technician III

- Digestive system

- Diabetes and glucagon

- Law and ambulance staff

- Major incidents

- Poisoning

- Extremities of body temperature

- Maternity

- Haemodialysis

- Acute abdominal problems

It therefore seems that the existing technician and paramedic curriculums do not equip clinical ambulance staff for practice, or with the necessary attributes demanded by the workload they experience. In respect of the clinical supervisor no nationally recognised curriculum exists and so it is difficult to make judgements about the adequacy of preparation for this role. However, given the lack of published work in this area it seems unlikely that aspects of best practice have been widely adopted and that preparation for clinical supervisory roles, if they exist at all, are formulated and delivered at a local level, with inherent variation in practice. The evolution of the clinical supervisor role seems to be following a similar pattern to the evolution of paramedic education in that activity is taking place at a local level in response to local needs and workforce planning without, at this stage, any national lead to evaluate theses schemes and recommend a model for practice and education.

It would seem that a review of the education of clinical ambulance staff is well overdue. The Department of Health in 2000 made their position clear on the issue of education of staff in the NHS stating that

"Radical reform is required in NHS education and training to reshape care around the patient" (DoH 2000: page 85$)^{10}$ 
Box 3 Components of the ambulance paramedic curriculum (IHCD ambulance personnel awards: training and common core syllabus for ambulance personnel)

Systems of the body

- The respiratory system

- The cardiovascular system

- The nervous system/observation and assessment

Trauma management and medical conditions

- Trauma care

- Thermal injuries

- Medical conditions

Paediatric and obstetric emergency care

- Paediatric care

- Obstetrics and gynaecology

This project therefore aimed to use established information about the desirable attributes of ambulance staff to propose an alternative curriculum framework for the education of clinical ambulance personnel.

\section{METHODS}

In an accompanying study the Delphi technique was used to solicit the consensus view of an expert panel as to the desirable attributes of the ambulance technician, paramedic, and clinical supervisor.' Chief executives and medical directors of ambulance trusts were invited to become members of the expert panel as were examiners for the Diploma in Immediate Medical Care, Royal College of Surgeons of Edinburgh.

In the first round of the study experts were invited to list the desirable attributes of the ambulance technician, paramedic, and clinical supervisor in four specific areas; attitudes and values, knowledge, intellectual skills, and psychomotor skills. The data from this round were subject to content analysis; the resultant themes were the basis for a series of attribute statements. In the second round of the study the experts were requested to rate each attribute statement, between not at all desirable and highly desirable, in respect of each occupational group on a $10 \mathrm{~cm}$ visual analogue scale. Consequently it has been possible to rank the desirable attributes for each of the occupational groups.

These data have been further analysed by means of factor analysis using the computer based SPSS statistical package. To undertake factor analysis Bryman and Kramer ${ }^{11}$ argue that there should be at least as many participants as items, which was achieved in this study. Factor analysis is a series of statistical tests used to reduce or simplify data, by examining correlation between variables, and therefore enabling the generation and exploration of theories. ${ }^{12}$ The process enables a number of attribute statements to be grouped into a smaller number of themes or factors, based upon the correlation between the variables. As Pallant ${ }^{13}$ suggests, factor analysis takes a large set of variables and looks for a way that the data may be reduced or summarised using a smaller set of factors or components. Therefore it may be possible to group attributes of clinical ambulance staff, identified in the Delphi study, into factors that represent modules or themes within a curriculum framework.

Exploratory factor analysis with orthoganol rotation was carried out on the data for each of the occupational groups. As Kline argues, rotation is desirable to account for observed correlations. ${ }^{12}$ Scree plots were calculated for each of the occupational groups to determine the number of factors to rotate.

\section{RESULTS}

Eighty six questionnaires were distributed in the second round of the Delphi study of which $42(48.8 \%)$ were returned completed and upon which the statistical analysis is based. By using the scree test, three rotated factors emerged for each of the occupational groups and are illustrated in tables 1, 2, and 3. These tables also show the extent to which elements loaded onto each factor. Variables loading 0.6 are regarded as being highly correlated with the factor and the correlation being moderately high if above $0.3^{12}$ In this case all variables loaded on at least one factor with a correlation of 0.3 or above.

To check internal validity of each factor, and therefore that attributes loading on the factor are measuring the same construct, Cronbach's $\alpha$ coefficient was calculated for each factor. Reliability is regarded as high where Cronbach's $\alpha$ coefficient is greater than $0.7 .{ }^{13}$ This was achieved in all factors relating to each of the occupational groups (see tables 1, 2, and 3)

The factors are assigned a label that reflects the content and best describes the curriculum theme. For the technician these may be described as; core professional skills, individual and collaborative approaches to health and safety, and the management of self and clinical situations. For the paramedic the themes are; core professional skills, management of self, and clinical situations, and approaches to health and safety. For the clinical supervisor there is again a theme described as core professional skills, with a further two themes described as role model and lifelong learning.

\section{DISCUSSION}

All 36 attributes loaded onto the three factors for each of the occupational groups. However, while the content of each factor is not identical there are some similarities. This would suggest that while the broad attributes required are the same for each occupational group the importance and the focus are different for each group. The relation between attributes within the factor may offer some indication as to the focus of teaching and the education programme. For example, the management of self and clinical situations for the technician and paramedic will be different. The technician may need greater emphasis on management of, their workload, their time or their own learning while for the paramedic these skills should have been developed as a technician and therefore there may be more emphasis on organising the workload of others, delegation, and supervision of junior staff.

It is also clear from the data that while all three occupational groups have a factor described as core professional skills, the content is different for each group, just as there are fundamental differences between the core role of the technician, paramedic, and clinical supervisor. However, the identified factors and the associated attributes may offer some guidance as to the type and nature of modules to include in educational programmes.

Current technician and paramedic training have a narrow focus on technical clinical skills and the transportation of the sick and injured. While the technical skills used by both technicians and paramedics have been updated over time, the curriculum continues to pay little if any attention to the broader repertoire of professional skills and attributes demonstrated in other healthcare disciplines such as critical thinking, familiarity with clinical governance and health policy, patient assessment, and autonomous practice. Many of these changes have occurred in other healthcare disciplines in response to a changing health service that has become more consumer led. 
Table 1 Factors relating to the ambulance technician

\begin{tabular}{|c|c|c|c|c|}
\hline \multicolumn{5}{|l|}{ Ambulance technician } \\
\hline \multirow[b]{2}{*}{ Label } & \multirow[b]{2}{*}{ Attribute } & \multicolumn{3}{|c|}{ Factor loadings } \\
\hline & & 1 & 2 & 3 \\
\hline \multirow[t]{23}{*}{$\begin{array}{l}\text { Factor } 1 \\
\text { Core professional skills } \\
\alpha=0.9534\end{array}$} & $\begin{array}{l}\text { A range of clinical skills to enable them to manage a range of common } \\
\text { emergency conditions, for example; first aid, life support, defibrillation, } \\
\text { airway management, drug administration }\end{array}$ & 0.786 & 0.000 & 0.000 \\
\hline & Patient centred & 0.776 & 0.000 & 0.000 \\
\hline & $\begin{array}{l}\text { Physically fit for the role, manually dextrous, with good hand eye } \\
\text { coordination }\end{array}$ & 0.767 & 0.000 & 0.000 \\
\hline & Role model for others & 0.762 & 0.000 & 0.316 \\
\hline & $\begin{array}{l}\text { Ability to learn, including the ability to use reflection and learn from } \\
\text { experience }\end{array}$ & 0.750 & 0.330 & 0.000 \\
\hline & Commitment to self development & 0.748 & 0.000 & 0.000 \\
\hline & Non-judgemental, non-discriminatory & 0.736 & 0.000 & 0.000 \\
\hline & Literate and numerate & 0.729 & 0.000 & 0.000 \\
\hline & Aware of and adherence to national and local guidelines and policies & 0.711 & 0.000 & 0.000 \\
\hline & Professionalism & 0.710 & 0.000 & 0.000 \\
\hline & Awareness of evidence based practice & 0.707 & 0.000 & 0.360 \\
\hline & Communication skills: written, verbal, and electronic & 0.695 & 0.382 & 0.000 \\
\hline & Caring, empathic, and values life & 0.690 & 0.000 & 0.000 \\
\hline & Underpinning knowledge in law and ethics & 0.686 & 0.000 & 0.000 \\
\hline & $\begin{array}{l}\text { Underpinning knowledge of common emergency conditions in adults } \\
\text { and children }\end{array}$ & 0.682 & 0.391 & 0.000 \\
\hline & $\begin{array}{l}\text { Awareness of and regard for professional issues such as: autonomy, } \\
\text { accountability, confidentiality and a code of professional conduct }\end{array}$ & 0.680 & 0.000 & 0.000 \\
\hline & Familiarity with emergency medical equipment and its operation & 0.670 & 0.523 & 0.000 \\
\hline & Self aware, recognising personal responsibility and limitations & 0.666 & 0.387 & 0.000 \\
\hline & Practical & 0.597 & 0.466 & 0.000 \\
\hline & $\begin{array}{l}\text { An understanding of current issues, clinical governance and the role of } \\
\text { others within the wider health economy }\end{array}$ & 0.549 & 0.000 & 0.401 \\
\hline & $\begin{array}{l}\text { Ability to take a history and conduct patient assessment and examination } \\
\text { of both adults and children }\end{array}$ & 0.542 & 0.416 & 0.422 \\
\hline & $\begin{array}{l}\text { Skills and knowledge from recognised emergency care courses such as: } \\
\text { prehospital trauma life support, advanced life support, prehospital } \\
\text { paediatric life support }\end{array}$ & 0.501 & 0.000 & 0.410 \\
\hline & Honest & 0.426 & 0.000 & 0.000 \\
\hline \multirow{7}{*}{$\begin{array}{l}\text { Factor } 2 \\
\text { Individual and collaborative } \\
\text { approaches to health and } \\
\text { safety } \\
\alpha=0.8157\end{array}$} & Familiarity with local operational area & 0.000 & 0.816 & 0.000 \\
\hline & Skills and underpinning knowledge of advanced driving & 0.000 & 0.727 & 0.000 \\
\hline & Skills and awareness of manual handling and health and safety & 0.448 & 0.670 & 0.000 \\
\hline & Team player with ability to work alone & 0.000 & 0.618 & 0.525 \\
\hline & Mental health skills & 0.355 & 0.586 & 0.000 \\
\hline & Brave & 0.000 & 0.575 & 0.000 \\
\hline & Common sense & 0.447 & 0.498 & 0.000 \\
\hline \multirow{6}{*}{$\begin{array}{l}\text { Factor } 3 \\
\text { Management of self and } \\
\text { clinical situations } \\
\alpha=0.8363\end{array}$} & Leadership, mentoring, and supervision & 0.000 & 0.000 & 0.796 \\
\hline & Skills in clinical and personnel management & 0.000 & 0.000 & 0.752 \\
\hline & Research, statistics, and information retrieval skills & 0.000 & 0.000 & 0.752 \\
\hline & Skills in teaching and presentation & 0.000 & 0.000 & 0.691 \\
\hline & $\begin{array}{l}\text { Intellectual skills to enable the interpretation of clinical data, the } \\
\text { implementation of clinical judgement and decision making and the } \\
\text { formulation of a diagnosis }\end{array}$ & 0.000 & 0.000 & 0.685 \\
\hline & $\begin{array}{l}\text { Underpinning knowledge in biological sciences including anatomy, } \\
\text { physiology, and pathology }\end{array}$ & 0.493 & 0.000 & 0.607 \\
\hline
\end{tabular}

While individual ambulance trusts have attempted to respond to the changing face of the health service, ambulance education has not. It is difficult to see how trusts can adequately respond to the demands of a modern health service while continuing to pursue training programmes that are philosophically the same as those developed over 20 years ago and for the technician more than 40 years ago.

What has emerged is the need for a curriculum that is far broader than existing technician and paramedic training programmes. Some components appear in both the existing ambulance curriculums as well as being identified in this study. However, only a small number of the attributes identified in this study are represented in the existing technician and paramedic programme. The data suggest that a programme broadly similar to those used to educate other health care is desirable. With factors being the basis of modules or programmes of study with the detailed content and assessment being guided by the factor loadings, especially as high degrees of internal validity within each factor have been demonstrated.

In 2001 the Quality Assurance Agency for Higher Education (QAA) developed benchmark statements for healthcare programmes. ${ }^{14}$ These statements were designed to offer guidance on the nature and characteristics of a programme of study and training in health care. A summary of these statements is outlined in table 4 (available to view on the journal web site http://www.emjonline.com/ supplemental). These statements have already been mapped to a number of healthcare programmes such as: dietetics, health visiting, midwifery, nursing, occupational therapy, orthoptics, physiotherapy, podiatry, prosthetics and orthotics, radiography, and speech and language therapy. As yet the statements have not been mapped to the training of ambulance staff but they do appear to be remarkably similar 
Table 2 Factors relating to the ambulance paramedic

\begin{tabular}{|c|c|c|c|c|}
\hline \multicolumn{5}{|l|}{ Ambulance paramedic } \\
\hline \multirow[b]{2}{*}{ Label } & \multirow[b]{2}{*}{ Attribute } & \multicolumn{3}{|c|}{ Factor loadings } \\
\hline & & 1 & 2 & 3 \\
\hline Factor 1 & Aware of and adherence to national and local guidelines and policies & 0.872 & 0.000 & 0.000 \\
\hline Core professional skills & Professionalism & 0.829 & 0.000 & 0.000 \\
\hline \multirow[t]{12}{*}{$\alpha=0.9527$} & $\begin{array}{l}\text { A range of clinical skills to enable them to manage a range of common } \\
\text { emergency conditions, for example; first aid, life support, defibrillation, } \\
\text { airway management, drug administration }\end{array}$ & 0.822 & 0.000 & 0.000 \\
\hline & Patient centred & 0.821 & 0.000 & 0.000 \\
\hline & $\begin{array}{l}\text { Underpinning knowledge of common emergency conditions in adults and } \\
\text { children }\end{array}$ & 0.811 & 0.360 & 0.000 \\
\hline & $\begin{array}{l}\text { Underpinning knowledge of biological sciences, including anatomy, } \\
\text { physiology, and pathology }\end{array}$ & 0.808 & 0.000 & 0.000 \\
\hline & $\begin{array}{l}\text { Ability to take a history and conduct patient assessment and examination } \\
\text { of both adults and children }\end{array}$ & 0.768 & 0.337 & 0.000 \\
\hline & Team player with ability to work alone & 0.745 & 0.000 & 0.520 \\
\hline & $\begin{array}{l}\text { Skills and knowledge from recognised emergency care courses such as: } \\
\text { prehospital trauma life support, advanced life support, prehospital paediatric } \\
\text { life support }\end{array}$ & 0.717 & 0.000 & 0.000 \\
\hline & Non judgemental, non-discriminatory & 0.706 & 0.000 & 0.000 \\
\hline & Commitment to self development & 0.666 & 0.342 & 0.424 \\
\hline & Caring, empathic, and values life & 0.633 & 0.352 & 0.413 \\
\hline & Role model for others & 0.631 & 0.381 & 0.000 \\
\hline & Self aware, recognising personal responsibility and limitations & 0.542 & 0.533 & 0.418 \\
\hline Factor 2 & Leadership, mentoring, and supervision & 0.000 & 0.800 & 0.000 \\
\hline $\begin{array}{l}\text { Management of self and } \\
\text { clinical situations }\end{array}$ & $\begin{array}{l}\text { Understanding of current issues, clinical governance, and the role of } \\
\text { others within the wider health economy }\end{array}$ & 0.303 & 0.776 & 0.000 \\
\hline \multirow[t]{13}{*}{$\alpha=0.9304$} & Skills in clinical and personnel management & 0.000 & 0.770 & 0.000 \\
\hline & Research, statistics, and information retrieval skills & 0.509 & 0.727 & 0.000 \\
\hline & Underpinning knowledge in law and ethics & 0.414 & 0.680 & 0.000 \\
\hline & Awareness of evidence based practice & 0.540 & 0.658 & 0.000 \\
\hline & Communication skills: written, verbal, and electronic & 0.485 & 0.641 & 0.000 \\
\hline & Mental health skills & 0.000 & 0.631 & 0.000 \\
\hline & $\begin{array}{l}\text { Awareness of and regard for professional issues such as: autonomy, } \\
\text { accountability, confidentiality, and a code of professional conduct }\end{array}$ & 0.534 & 0.604 & 0.307 \\
\hline & Literate and numerate & 0.343 & 0.563 & 0.326 \\
\hline & $\begin{array}{l}\text { Physically fit for the role, manually dextrous, with good hand eye } \\
\text { coordination }\end{array}$ & 0.461 & 0.562 & 0.000 \\
\hline & $\begin{array}{l}\text { Intellectual skills to enable the interpretation of clinical data, the } \\
\text { implementation of clinical judgement and decision making and the } \\
\text { formulation of a diagnosis }\end{array}$ & 0.412 & 0.517 & 0.359 \\
\hline & Familiarity with emergency medical equipment and its operation & 0.393 & 0.511 & 0.323 \\
\hline & Skills in teaching and presentation & 0.000 & 0.483 & 0.382 \\
\hline & Honest & 0.000 & 0.347 & 0.000 \\
\hline \multirow{7}{*}{$\begin{array}{l}\text { Factor } 3 \\
\text { Approaches to health and } \\
\text { safety } \\
\alpha=0.8479\end{array}$} & Common sense & 0.000 & 0.000 & 0.856 \\
\hline & Familiarity with local operational area & 0.000 & 0.000 & 0.814 \\
\hline & Practical (pragmatic) & 0.000 & 0.000 & 0.790 \\
\hline & $\begin{array}{l}\text { Ability to learn, including the ability to use reflection and learn } \\
\text { from experience }\end{array}$ & 0.322 & 0.000 & 0.696 \\
\hline & Skills and underpinning knowledge of advanced driving & 0.370 & 0.000 & 0.370 \\
\hline & Skills and awareness of manual handling and health and safety & 0.000 & 0.384 & 0.584 \\
\hline & Brave & 0.000 & 0.373 & 0.501 \\
\hline
\end{tabular}

to the attributes required of ambulance staff outlined in this paper. Ambulance specific content could be mapped to these statements as occupation specific content from other disciplines, such as nursing or physiotherapy, has been.

It may be that a case is emerging to bring the training and education of ambulance staff in line with the education and training of other healthcare professionals. Currently the training of the ambulance technician and paramedic is delivered in service once people have been employed by the ambulance trust. Conversely most other healthcare providers undertake training, generally lasting three years, leading to qualification before employment within the healthcare sector. In the case of technician training the taught component consists of three weeks of driver training and six weeks of clinical training. While this is followed by a year of operational experience before the full award most of this is rostered operational activity. For the paramedic, clinical training lasts six weeks with in hospital experience of a further four weeks. Again this is followed up with six months of operational activity as consolidation. Unlike other healthcare disciplines where the exit qualification is at either diploma or first degree level ambulance service education does not appear to be accredited within that type of framework.

There are exceptions to this model in the United Kingdom, with a small number of higher education institutions who deliver programmes, which incorporate both the broader issues of professional practice and the IHCD awards of ambulance technician and ambulance paramedic in a preregistration paramedic programme. However, even with these programmes it is the IHCD award that is the qualification to practice and not the additional components. There are also an equally small number of higher education institutions offering post-qualification, paramedic diploma, and degree programmes. Given this is a very small provision the number 
Table 3 Factors relating to the ambulance clinical supervisor

\begin{tabular}{|c|c|c|c|c|}
\hline \multicolumn{5}{|c|}{ Ambulance clinical supervisor } \\
\hline \multirow[b]{2}{*}{ Label } & \multirow[b]{2}{*}{ Attribute } & \multicolumn{3}{|c|}{ Factor loadings } \\
\hline & & 1 & 2 & 3 \\
\hline \multirow{15}{*}{$\begin{array}{l}\text { Factor } 1 \\
\text { Core professional skills } \\
\alpha=0.9428\end{array}$} & Awareness of evidence based practice & 0.901 & 0.000 & 0.000 \\
\hline & Leadership, mentoring, and supervision & 0.851 & 0.000 & 0.000 \\
\hline & Research, statistics, and information retrieval skills & 0.837 & 0.000 & 0.000 \\
\hline & Underpinning knowledge in law and ethics & 0.818 & 0.364 & 0.000 \\
\hline & $\begin{array}{l}\text { Underpinning knowledge of biological sciences, including anatomy, } \\
\text { physiology, and pathology }\end{array}$ & 0.799 & 0.000 & 0.000 \\
\hline & $\begin{array}{l}\text { An understanding of current issues, clinical governance and the role of } \\
\text { others within the wider health economy }\end{array}$ & 0.754 & 0.000 & 0.000 \\
\hline & $\begin{array}{l}\text { Awareness of and regard for professional issues such as: autonomy, } \\
\text { accountability, confidentiality, and a code of professional conduct }\end{array}$ & 0.736 & 0.446 & 0.000 \\
\hline & Literate and numerate & 0.733 & 0.000 & 0.000 \\
\hline & $\begin{array}{l}\text { Skills and knowledge from recognised emergency care courses such as: } \\
\text { prehospital trauma life support, advanced life support, prehospital paediatric } \\
\text { life support }\end{array}$ & 0.723 & 0.000 & 0.326 \\
\hline & $\begin{array}{l}\text { A range of clinical skills to enable them to manage a range of common } \\
\text { emergency conditions, for example; first aid, life support, defibrillation, } \\
\text { airway management, drug administration }\end{array}$ & 0.712 & 0.339 & 0.000 \\
\hline & Skills in clinical and personnel management & 0.712 & 0.000 & 0.000 \\
\hline & Familiarity with emergency medical equipment and its operation & 0.595 & 0.586 & 0.000 \\
\hline & $\begin{array}{l}\text { Underpinning knowledge of common emergency conditions in adults and } \\
\text { children }\end{array}$ & 0.587 & 0.385 & 0.000 \\
\hline & Communication skills: written, verbal, and electronic & 0.461 & 0.000 & 0.000 \\
\hline & $\begin{array}{l}\text { Intellectual skills to enable the interpretation of clinical data, the } \\
\text { implementation of clinical judgement and decision making, and the } \\
\text { formulation of a diagnosis }\end{array}$ & 0.453 & 0.420 & 0.000 \\
\hline \multirow{14}{*}{$\begin{array}{l}\text { Factor } 2 \\
\text { Role model } \\
\alpha=0.948\end{array}$} & Caring, empathic, and values life & 0.000 & 0.860 & 0.000 \\
\hline & Patient centred & 0.000 & 0.846 & 0.000 \\
\hline & Non judgemental, non-discriminatory & 0.000 & 0.825 & 0.000 \\
\hline & $\begin{array}{l}\text { Ability to take a history and conduct patient assessment and examination } \\
\text { of both adults and children }\end{array}$ & 0.406 & 0.810 & 0.000 \\
\hline & Honest & 0.000 & 0.810 & 0.000 \\
\hline & Common sense & 0.341 & 0.770 & 0.000 \\
\hline & Mental health skills & 0.000 & 0.726 & 0.000 \\
\hline & Professionalism & 0.485 & 0.715 & 0.000 \\
\hline & Practical (pragmatic) & 0.359 & 0.685 & 0.000 \\
\hline & Aware of and adherence to national and local guidelines and policies & 0.562 & 0.668 & 0.000 \\
\hline & $\begin{array}{l}\text { Physically fit for the role, manually dextrous with good hand eye } \\
\text { coordination }\end{array}$ & 0.000 & 0.663 & 0.000 \\
\hline & Role model for others & 0.000 & 0.614 & 0.304 \\
\hline & Team player with ability to work alone & 0.414 & 0.521 & 0.000 \\
\hline & Self aware, recognising personal responsibility and limitations & 0.508 & 0.511 & 0.475 \\
\hline \multirow{7}{*}{$\begin{array}{l}\text { Factor } 3 \\
\text { Lifelong learning } \\
\alpha=0.8375\end{array}$} & $\begin{array}{l}\text { Ability to learn, including the ability to use reflection and learn from } \\
\text { experience }\end{array}$ & 0.000 & 0.000 & 0.919 \\
\hline & Skills in teaching and presentation & 0.361 & 0.000 & 0.845 \\
\hline & Commitment to self development & 0.485 & 0.326 & 0.702 \\
\hline & Skills and awareness of manual handling and health and safety & 0.000 & 0.546 & 0.657 \\
\hline & Skills and underpinning knowledge of advanced driving & 0.000 & 0.412 & 0.594 \\
\hline & Familiarity with local operational area & 0.000 & 0.425 & 0.558 \\
\hline & Brave & 0.000 & 0.389 & 0.448 \\
\hline
\end{tabular}

of people qualifying from this route is extremely small when compared with the vast majority qualifying through the traditional IHCD route and therefore do not benefit from a curriculum that includes many of the broader professional issues.

It is difficult to see how, even accounting for some study time within the consolidation period for technicians and paramedics, how an expanded curriculum could be delivered in service within the current time frame. The programme outlined in this study, based upon the attributes experts have agreed as desirable in clinical ambulance staff, has many similarities with programmes for other healthcare providers that are delivered over a longer period of time and within a higher education framework. This will of course have significant implications for funding of ambulance service education, workforce planning, selection of staff, and transitional arrangements for staff who have undertaken traditional training.

\section{CONCLUSION}

As Lendrum and colleagues ${ }^{8}$ have shown, the existing technician and paramedic training does not deliver the range of skills necessary in a modern healthcare system, it is highly skills focused with emphasis on the management of those with life threatening conditions, but who are comparatively uncommon in the workload profile of ambulance staff. Conversely little attention is paid to those conditions that the technician and paramedic are likely to encounter. The curriculum offers little in terms of educational preparation of clinical ambulance staff in areas of professional practice beyond this technical focus, for example in areas of research, evidence based practice, clinical decision making, cultural awareness, self development, and lifelong learning. This study proposes curriculum content for the education of the technician, paramedic, and clinical supervisor using empirical data rather than assumption. The factors may provide the basis for modules or programmes of study with the factor 
loadings offering the detailed content and guidance for assessment. The content of the themes differs between each of the professional groups reflecting the fundamental differences in role. Skills in teaching and presentation for the technician may be focused upon patient education such as the use of an inhaler, while the same category for the clinical supervisor may be more focused upon the professional development of staff within a clinical team, for example. Many of these attributes and curriculum themes are reflected in the QAA benchmark statements for healthcare programmes.

There seems to be a case emerging to support the need for an expanded curriculum to prepare clinical ambulance staff to reflect the demands of a modern consumer led health service. This may take the form of a new curriculum for the training of clinical ambulance staff, but the findings of this study may also have a use in informing the continuing professional development of existing staff who have undertaken a traditional training programme. However, the implementation of any new curriculum will have important political, resource, and organisational implications.

\section{ACKNOWLEDGEMENTS}

Thanks to Professor Carolyn Hicks for advice on methodology and data analysis, and for commenting on early drafts of this paper.

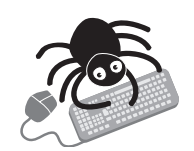

Please visit the journal web site (http://www. emjonline.com/supplemental) to see a summary of QAA benchmark statements for healthcare programmes.
Funding: none.

Conflicts of interest: TK is the principal and subject examiner for the certificate, diploma, and degree in paramodic sciences at the University of Hertfordshire. He is also a member of JRCALC. This paper is also part of work contributing to his PhD studies.

\section{REFERENCES}

1 Ministry of Health, Scottish Home and Health Department. Report by the working party on ambulance training and equipment: part 1-training. London: HMSO, 1966.

2 Ministry of Health, Scottish Home and Health Department. Report by the working party on ambulance training and equipment: part 2-equipment and vehicles. London: HMSO, 1967.

3 Spears R. Patients are people: an account of the Salford Ambulance Service 1948-1974. Manchester: Neil Richardson, 1994.

4 IHCD. IHCD ambulance personnel awards: training and common core syllabus for ambulance personnel. London: Ambulance Service Association, 2000.

5 Pantridge J. Manning mobile intensive care units. Lancet 1967; ii:888.

6 Wright K. Extended training of ambulance staff. York: University of York, Institute for Research in the Social Sciences, Centre for Health Economics, 1984.

7 IHCD. Paramedic training rules and regulations. Bristol: Institute of Health and Care Development, 2003.

8 Lendrum K, Wilson S, Cooke MW. Does the training of ambulance personnel match the workload seen? Pre-hospital Immediate Care 2000;4:7-10.

9 Kilner T. Desirable attributes of ambulance technician, paramedic, and clinical supervisor: findings from a Delphi study. Emerg Med J 2004;21:374-8.

10 Department of Health. The NHS plan. London: HMSO, 2000.

11 Bryman A, Cramer D. Quantitative data analysis with SPSS for Windows. London: Routledge, 1997.

12 Kline P. An easy guide to factor analysis. London: Routledge, 1994.

13 Pallant J. SPSS survival manual. Buckingham: Open University Press, 2001.

14 QAA. Benchmark statement: health care programmes. Gloucester: The Quality Assurance Agency for Higher Education, 2001. 